\title{
Hybrid capture II, a new sensitive test for human papillomavirus detection. Comparison with hybrid capture I and PCR results in cervical lesions
} Christine Clavel, Marie Masure, Isabelle Putaud, Kathleen Thomas, Jean-Paul Bory,
René Gabriel, Christian Quereux, Philippe Birembaut
CHU Reims, Reims, France Cell Biology Unit, Laboratoire Pol Bouin C Clavel

M Masure

I Putaud

K Thomas

P Birembaut

Department of Obstetrics and Gynaecology

J-P Bory

R Gabriel

C Quereux

Correspondence to: Dr Christine Clavel, Laboratoire Pol Bouin, Hôpital Maison Blanche, 45 rue Cognacq-Jay, 51100 Reims, France.

Accepted for publication 8 June 1998

\begin{abstract}
Aim-To test a new assay for the detection of human papillomavirus (HPV) DNA, hybrid capture II (HC II), compared with the previous commercialised hybrid capture I (HC I) and polymerase chain reaction (PCR) results on cervical scrapes from fresh cone excision biopsy samples. Methods-The three methods were used on cervical scrapes from 42 fresh cone excision biopsy samples. There were nine metaplastic and inflammatory lesions, five low grade lesions, and 28 high grade lesions. PCR was performed using the general primers GP5+/GP6+. The viral load of high risk HPV DNA was estimated by the ratio of relative light units to positive control values in the samples.

Results-The sensitivity of HC I for the detection of high grade lesions was $71.4 \%$, while it was $92.8 \%$ for HC II and $96.4 \%$ for the PCR. Considering only the absence of detectable cervical in situ neoplasia, the specificity was $88.9 \%$ for HC I, $66.7 \%$ for HC II, and $66.7 \%$ for PCR. With HC II, for a ratio of cervical sample to normal control of $>200$, the sensitivity for the detection of high grade lesion was only $34.6 \%$ with a specificity of $66.7 \%$.

Conclusions-HPV detection with the HC II assay is more sensitive than the previous HC I and represents a more convenient and easier test than PCR for routine use. Nevertheless the viral load estimated with this test cannot be a reliable predictive indicator of high grade lesions. (F Clin Pathol 1998;51:737-740)
\end{abstract}

Keywords: hybrid capture; human papillomavirus; cervical intraepithelial neoplasia

DNA of the high risk human papillomavirus (HPV) types (including types 16, 18, 31, 33, 35 , and 39 ) is found in over $90 \%$ of cervical cancers and in their precursor lesions, while the low risk HPV types (including types 6 and 11) are associated almost exclusively with benign lesions. ${ }^{1-4}$ Infections with high risk HPV are associated with a relative risk of between 8 and 11 for the development of squamous inraepithelial lesions (SIL) 5 and only low grade SIL containing high risk HPV types progress to high grade disease. ${ }^{6}$ This is the reason for the increasing interest in using HPV DNA detection, either alone or in addition to classical cytological examination, as a method for screening cervical carcinoma or for triaging women with a cytological diagnosis of atypical squamous cells of undetermined significance (ASCUS) in their cervical smears. ${ }^{7-9} \mathrm{HPV}$ DNA testing in exfoliated cervical cells offers a potentially automatic and cheap diagnostic assay without the sampling problems and subjectivity of cervical cytology. However, such an approach needs a specific, sensitive, reliable, and easy to perform method. The polymerase chain reaction (PCR) is the best and most sensitive test to date. Moreover, its routine application is very much improved by using a non-radioactive enzyme immunoassay detection procedure. ${ }^{10-12}$ These methods are not yet commercially available; however, they can be applied on a large scale. ${ }^{10}$

Three years ago, a commercial HPV detection test, hybrid capture (HC), was introduced. ${ }^{13-15}$ Hybrid capture is a nonradioactive, relatively rapid, liquid hybridisation assay designed to detect $14 \mathrm{HPV}$ types, divided into high risk (types 16, 18, 31, 33, 35, $45,51,52$, and 56) and low risk (types 6, 11, 42,43 , and 44) groups. This test has been proposed for routine use on large series of women to improve the sensitivity and negative predictive value of screening for SIL. ${ }^{16}$ It can be applied to biopsy specimens ${ }^{17}$ and cervical lavage ${ }^{14}$ but its principal application is with cervical scrapes. The first studies were particularly promising, showing a good agreement with PCR results, although the method was less sensitive, with detection rates for high risk HPV DNA of $83 \%$, and $93 \%$ for high grade SIL. ${ }^{8} 13$ These papers and the following studies of selected populations concluded that screening for cervical intraepithelial neoplasias (CIN) grades $2 / 3$ could be significantly improved by HPV testing with the hybrid capture assay. Nevertheless, in our own experience on a series of 1028 women attending routine screening, the overall sensitivity in detecting high grade SIL with hybrid capture was $71.2 \%$ and its positive predictive value was $17.8 \% .{ }^{18}$ Classical cytological screening remained the most sensitive tool $(84 \%)$ to detect high grade SIL, with a positive predictive value of $91.3 \%$. Thus we concluded that the crude sensitivity of the hybrid capture limited its use for the screening of high grade lesions on a large scale.

Since this study, a second generation of hybrid capture has been commercialisedhybrid capture II (Digene) (HC II), using microtitre plates instead of tubes and detecting four additional viral oncogenic types (types 39, 58, 59 and 68). The preliminary studies give 
Table 1 Results obtained with the three techniques

\begin{tabular}{llllllll}
\hline & \multicolumn{3}{c}{ Negative HPV } & & & \multicolumn{3}{c}{ Oncogenic positive HPV } \\
\cline { 2 - 3 } Lesions & HCI & HC II & PCR & & HC I & HC II & PCR \\
\hline 9 INFL & 8 & 6 & 6 & & 1 & 3 & 3 \\
5 LG & 3 & 2 & 1 & & 2 & 3 & 4 \\
28 HG & 8 & 2 & 1 & & 20 & 26 & 27
\end{tabular}

HC, hybrid capture; HG, high grade lesions; HPV, human papillomavirus; INFL, metaplastic and inflammatory lesions; LG, low grade lesions; PCR, polymerase chain reaction.

more reliable results, with a lower detection limit of 0.2 to $1 \mathrm{pg} \mathrm{HPV} \mathrm{DNA} / \mathrm{ml}^{19}$ The aim of the our present study on a series of fresh cone biopsy samples was not only to confirm the presence of high risk HPV in cervical lesionswhich is well known, especially with PCR analysis - but also to evaluate the sensitivity and specificity of HC II test as compared with the results obtained with the previous hybrid capture assay (HC I) and data provided by PCR for HPV detection in routine clinical use.

\section{Methods}

We studied 42 fresh cone excision biopsy samples following the discovery of high grade SIL on a previous biopsy. Cervical cells were collected with cytobrushes (Medscan) on fresh samples just before surgery. Specimens for HPV DNA testing were suspended in $1 \mathrm{ml}$ of ViraPap/Viratype transport medium (Digene) and stored at $-20^{\circ} \mathrm{C}$ until further processing. The same cervical scrape was used for the HC I and HC II tests and $200 \mu \mathrm{l}$ of the sample were stored for PCR.

HPV DNA detection was performed by the two commercially available hybrid capture techniques (Digene): HC I and HC II. All scrapes were analysed for the presence of low risk HPV types 6, 11, 42, 43, and 44 and high risk HPV types $16,18,31,33,35,45,51,52$, and 56. Types $39,58,59$, and 68 only were detected with the HC II assay. This enzyme linked immunosorbent assay is based on a sandwich hybridisation followed by a nonradioactive alkaline phosphatase reaction with chemiluminescence in tubes (HC I) and in microplates (HC II).

Samples were classified as positive for HPV DNA if the relative light unit reading obtained from the luminometer was equal to or greater than the mean of the positive control values. As some investigators have reported that increased HPV DNA level of high risk HPV types was the principal predictor of $\mathrm{CIN}^{8}$, we used as proposed the ratio of relative light units to positive control values to quantify high risk HPV DNA in our samples.

In parallel, we performed PCR according the protocol of de Roda Husman et al using GP5+/ GP6+ primers, ${ }^{20}$ after DNA extraction from the cervical scrapes to detect HPV DNA. This method allows the detection of $23 \mathrm{HPV}$ types (types $6,11,13,16,18,30,31,32,33,34,35$, $39,40,43,45,51,52,54,55,56,58,59$, and 66). The typing of HPV was performed by dotblot on amplimers with digoxygenin labelled HPV plasmid probes for HPV types 6, 11, 16, $18,31,33$, and 35.
Table 2 Evaluation of the viral load by HC II for the detection of high grade lesions

\begin{tabular}{|c|c|c|c|c|c|}
\hline $\begin{array}{l}\text { Viral load } \\
\text { (ratio) }\end{array}$ & $I N F L$ & $L G$ & $H G$ & Sensitivity & Specificity \\
\hline$<50$ & 1 & 2 & 10 & $100.00 \%$ & $0.00 \%$ \\
\hline $50-100$ & 0 & 1 & 4 & $61.54 \%$ & $50.00 \%$ \\
\hline $100-200$ & 1 & 0 & 3 & $46.15 \%$ & $66.66 \%$ \\
\hline $200-500$ & 0 & 0 & 5 & $34.61 \%$ & $66.66 \%$ \\
\hline$>500$ & 1 & 0 & 4 & $15.38 \%$ & $83.33 \%$ \\
\hline
\end{tabular}

The whole of the cone excision biopsy sample was embedded in paraffin and histological examination was performed on serial tissue sections.

\section{Results}

Table 1 summarises all the results obtained with the three techniques.

The lesions observed were: nine metaplastic and inflammatory lesions without any residual SIL, five low grade lesions (CIN1), and 28 high grade lesions (CIN2-3), including one invasive carcinoma.

In the nine cases without any CIN, HC I was positive in one case (oncogenic HPV), HC II in three cases (oncogenic HPV), and PCR in three cases (HPV type 16).

In the five low grade lesions, oncogenic HPV were detected in two cases with HC I, in three cases with HC II, and in four cases with PCR (two HPV type 16 and two HPV type 33). In one low grade lesion, HC II missed one HPV 33 detected by PCR.

In the 28 high grade lesions, oncogenic HPV were detected in 20 cases with HC I and in 26 cases with HC II. PCR gave positive results in 27 cases (17 HPV type 16, two HPV type 18 , one HPV type 31, four HPV type 33, and three undetermined types). In one high grade lesion, an undetermined type was detected by PCR. It may correspond to one of the uncommon HPV types undetected by HC II (HPV types 13, 30, $32,34,40,54,55$, and 66 ) or be related to a lower sensitivity of this test.

The cases positive with the three techniques (HC I, HC II, and PCR) were identical.

Thus the sensitivity of HC I for the detection of high grade lesions was $71.4 \%$, while it was $92.8 \%$ for HC II, and $96.4 \%$ for the PCR.

If we consider only the absence of detectable CIN, the specificity was $88.9 \%$ for HC I and $66.7 \%$ for both HC II and PCR. The positive predictive value of the detection of oncogenic HPV in high grade lesions was $86.9 \%$ for HC I, $81.2 \%$ for HC II, and $79.4 \%$ for the PCR.

The viral load in high grade lesions detected by HC I varied between a ratio of 1.2 and 199. ${ }^{18}$

With the HC II assay, the relative light unit ratio was between 1.3 and 1794 in high grade lesions. The values obtained in the three low grade lesions were $5.1,34.9$, and 64.1 , while in the three metaplastic and inflammatory cervical lesions they were 3, 189.4, and 676.6.

In five patients, we were able to compare the results of HC II before cone excision biopsy and on the fresh samples (time interval one month). Positivity and viral loads were identical, showing good reproducibility of the assay. 
Table 3 Evaluation of the viral load by HC II according to the maximum size of cervical intraepithelial neoplasia

\begin{tabular}{lllll}
\hline $\begin{array}{l}\text { Viral load } \\
\text { (ratio) }\end{array}$ & $1-3 \mathrm{~mm}$ & $3-5 \mathrm{~mm}$ & $5-10 \mathrm{~mm}$ & $>10 \mathrm{~mm}$ \\
\hline$<50$ & 4 & 3 & 2 & 3 \\
$50-100$ & 1 & 2 & 1 & 1 \\
$100-200$ & 1 & 0 & 1 & 1 \\
$200-500$ & 1 & 3 & 1 & 0 \\
$>500$ & 2 & 1 & 0 & 1 \\
\hline
\end{tabular}

HC, hybrid capture.

Table 2 shows the evaluation of the viral load for the detection of high grade lesions obtained by HC II. Table 3 shows the evaluation of the viral load according to the maximum size of the CIN in our specimens.

\section{Discussion}

In this study we compare the data obtained with three techniques detecting HPV DNA used for the detection of high grade lesions. We emphasise that the entire cone excision biopsy sample was histologically examined and so the final diagnosis of the lesions was definitive. This approach allowed us to obtain a good correlation between HPV detection and the cervical lesions. We did not detect any low risk HPV. This is not surprising since all of our cone excision biopsies were justified by previous histological diagnoses of high grade lesions generally related to high risk HPV. In 14 samples (nine inflammatory and five low grade lesions), high grade lesions were not detected. The previous biopsy may have excised the initial lesion. PCR remains the most sensitive method for detecting HPV DNA (27 of 28 high grade lesions $(96.4 \%)$, with a specificity of $66.7 \%$ ). HC II had a sensitivity of $92.8 \%$ and a specificity of $66.7 \%$, while HC I had a sensitivity of $71.4 \%$ and a specificity of $88.9 \%$. These latter results confirm our previous data on the sensitivity of HC I tested on cone biopsy samples ${ }^{18}$ and the findings of Nindl et al using the same comparative methodology on high grade cervical lesions. ${ }^{21}$ Our results with HC II were almost equivalent to those obtained with PCR. This rapid (five hours of handling), reliable, and sensitive assay seems very promising for detecting HPV DNA in routine clinical practice.

Cuzick et al showed that in women with cytological abnormalities, HPV positivity at a high level, detected by a semiquantitative PCR, was strongly related to high grade CIN. ${ }^{22} \mathrm{Ho}$ et al have also suggested that cases of SIL with a high viral load are more likely to persist than those with a low level of HPV DNA. ${ }^{23}$ Thus a high viral load of oncogenic HPV DNA may be considered a risk factor for potentially evolving low grade lesions as well as in high grade lesions. This variable can be semiquantitatively evaluated by the relative light unit values provided by the hybrid capture assay. Indeed, in none of the nine cases showing a low viral load $(<30)$ with the more sensitive HC II was high risk HPV DNA detected with HC I. Nevertheless, high grade lesions were not systematically associated with a high viral load. In our experience, for a ratio of cervical sample to normal control of $>200$, the sensitivity for the detection of high grade lesions was only $34.6 \%$, with a specificity of $83.3 \%$. We had similar findings with the previous HC I assay. ${ }^{18}$ The variability of the viral loads in high grade lesions may be explained by the low amount of oncogenic HPV DNA detectable when the viral DNA is integrated in the host genome, while in other circumstances viral DNA may also be present and abundant in its episomal form. The size of the lesions may also determine the numbers of exfoliated infected cells in cervical scrapes. However, we did not find any significant correlation between extension of the CIN and the viral load detected by the HC II assay in our cone excision biopsy samples (table 3). Thus the quantitative approach provided by the HC II cannot clearly discriminate between cases with and without high grade lesions.

In conclusion, HPV detection with the HC-II assay is more sensitive than the previous HC I. It represents a rapid and promising test for routine use. Nevertheless the viral load detected by this test was not a reliable predictor of high grade lesions. Thus the utility and efficacy of HPV detection with HC II needs to be compared with non-radioactive GP5+/6+ PCR for detecting high grade lesions in routine screening on larger populations.

This work was supported by the CHU (Centre Hospitalier et Universitaire) of Reims, the ARC (Association pour la Recherche contre le Cancer), and the Lion's Clubs of Soissons and Villers Cotterets. Bosch FX, Manos MM, Munoz N, et al and International Prevalence of worldwide perspective. $\mathcal{F}$ Natl Cancer Inst 1995;87:796802.

2 Lorincz AT, Reid R, Jenson AB, et al. Human papillomavirus infection of the cervix: relative risk association of 15 Van den Brule AJC, Walboomers AJM, Du Maine M, et al. Difference in prevalence of human papillomavirus genoDifference in prevalence of human papillomavirus genotypes in cytomorphologically normal smears is associated with a history of cervica

4 Zur Hausen H. Molecular pathogenesis of cancer of the cervix and its causation by specific human papillomavirus vix and its causation by specific human papillom
types. Curr Top Microbiol Immunol 1994;186:131-56.

5 Koutsky LA, Holmes KK, Critchlow CW, et al. A cohort study of the risk of cervical intraepithelial neoplasia grade 2 or 3 in relation to papillomavirus infection. $N$ Engl f Med 1992;327:1272-8.

6 Gaarenstrom KN, Melkert P, Walboomers JMM, et al. Human papillomavirus DNA genotypes: prognostic factors for progression of cervical intraepithelial neoplasia. Int $f$ Gynecol Cancer 1994;4:73-8.

7 Cole HM. Human papillomavirus DNA testing in the management of cervical neoplasia. $7 A M A$ 1993;270:2975-81.

8 Cox JT, Lorincz AT, Schiffman MH, et al. Human papillomavirus testing by hybrid capture appears to be useful in mavirus testing by hybrid capture appears to be useful in triaging women with a cytologic diagnosis of atypical Squamous cells of undeterm

9 Richart RM, Wright TC. Controversies in the management of low grade cervical intraepithelial neoplasia. Cancer 1993; of low grade cerv

10 Jacobs MV, Snidjers PJF, Van den Brule AJC, et al. A general primer GP5+/GP6+ mediated PCR-enzyme immunoassay method for rapid detection of 14 high-risk and 6 low-risk human papillomavirus genotypes in cervical scrapings. $\mathcal{F}$ Clin Microbiol 1997;35:791-5

11 Lungu O, Sun XW, Wright TC, et al. A polymerase chain reaction-enzyme linked immunosorbent assay method detecting human papillomavirus in cervical carcinomas and high-grade cervical cancer precursors. Obstet Gynecol 1995;85:337-42.

12 Clavel C, Rihet S, Masure M, et al. DNA-EIA to detect high and low risk HPV genotypes in cervical lesions with E6/E7 primer mediated multiplex PCR. F Clin Pathol 1998;51:3843.

13 Farthing A, Masterson P., Mason WP, et al. Human papilloFarthing A, Masterson P., Mason WP, et al. Human papillo-
mavirus detection by hybrid capture and its possible clinimavirus detection by hybrid capture a

14 Schiffman MA, Kiviat NB, Burk RD, et al. Accuracy and interlaboratory reliability of human papillomavirus DNA testing by hybrid capture. f Clin Microbiol 1995;33:545-50. 
15 Sun XW, Ferenczy A, Johnson D, et al. Evaluation of the hybrid capture human papillomavirus deoxyribonucleic

16 Hatch KD, Scheider A, Addel-Nour MW. An evaluation of human papillomavirus testing for intermediate- and high-risk types as triage before colposcopy. Am $\mathcal{F}$ Obstet Gynecol 1995;172:1150-7.

17 Brown DR, Rawlings K, Handy V, et al. Human papillomavirus detection by hybrid capture in paired cervicovaginal lavage and cervical biopsy specimens. F Med Virol 1996;48 $210-4$

18 Clavel C, Bory JP, Rihet S, et al. Comparative analysis of the human papillomavirus detection by hybrid capture assay and routine cytologic screening to detect high grade cervical lesions. Int $\mathcal{F}$ Cancer 1998;75:525-8.

19 Lorincz AT. Hybrid capture method for detection of human papillomavirus DNA in clinical specimens. Papillomavirus Rep 1996;7:1-5.
20 De Roda Husman AM, Walboomers JM, Van den Brule AJC, et al. The use of general primers GP5 and GP6 elongated at their 3 ' ends with adjacent highly conserved sequences improves human papillomavirus detection by PCR. F Gen Virol 1995;76:1057-62.

21 Nindl I, Zahm DM, Meijer CJLM, et al. Human papillomavirus detection in high-grade squamous intraepithelial lesions. Comparison of hybrid capture assay with a polymerase chain reaction system. Diagn Microbiol Infect Dis 1995;23:161-4

22 Cuzick J, Terry G, Ho L, et al. Human papillomavirus DNA in abnormal smears as a predictor of high-grade cervical intraepithelial neoplasia. Br f Cancer 1994;69: $167-71$

23 Ho GYF, Burk RD, Klein S, et al. Persistent genital human papillomavirus infection as a risk factor for persistent cervical dysplasia. F Natl Cancer Inst 1995;87:1365-71. 